\title{
The Role of APACHE II, SOFA, Serum amylase and Lipase in Assessment of Severity and Outcome of Acute Organophosphorus Poisoning
}

\author{
Mona E. Moussa', Soheir A. Mohamed, Maha A. Hilal, Marwa A. Hasb Elnabi ${ }^{2}$ and Nayel A. Zaki ${ }^{3}$ \\ ${ }^{1}$ Department of Forensic Medicine \& Clinical Toxicology, Faculty of Medicine, Ain Shams University, Cairo, Egypt. \\ 2 Department of Forensic Medicine \& Clinical Toxicology, Faculty of Medicine, Sohag University, Sohag, Egypt. \\ ${ }^{3}$ Department of Internal medicine, Faculty of Medicine, Sohag University, Sohag, Egypt.
}

\begin{abstract}
Poisoning with Organophosphate (OP) compounds is responsible for great morbidities and mortalities all over the world especially in developing countries including Egypt. Scoring systems have been continuously developed to predict outcomes in patients with severe illness, to improve resource allocation and to assist in clinical decision-making particularly for ICU patients. The quest for biomarkers in relation to OP compound poisoning started quite a long time back but cheap and easily measurable biomarkers having prognostic value is the need of the hour. The objective of this study is to evaluate the role of acute physiology and chronic health evaluation II (APACHE II) score, the Sequential Organ Failure Assessment (SOFA) score, serum amylase and lipase in assessing severity and outcome of acute organophosphorus poisoning. A retrospective and prospective study was carried out on 200 patients of acute OP poisoning admitted to the Poison Control Center (PCC), Ain Shams University Hospitals. Information after obtaining the permission of the director of PCC and the regional ethics committee was collected from the sheets and computerized data base of the patients, an informed written consent has been obtained from each patient or from his/her caregiver for inclusion in the prospective part of the study. APACHE II and SOFA scores were calculated to each patient admitted and biochemical analysis of serum amylase and lipase were estimated in the prospective part of the study. The results were revised, coded and organized for statistical analysis. The study results revealed 180 (90\%) patients discharged and 20 (10\%) patients died. The study showed that there were $76 \%$ of patients had APACHE II score $\leq 9$, while $12.5 \%$ of patients had APACHE II score from 10 to 14, there were 8.5\% of patients had APACHE II score from 15 to 24 and APACHE II score was > 24 in 3\% of patients. SOFA score in $88.5 \%$ of patients was $\leq 6$, while in $4.5 \%$ of patients SOFA score was from 7 to 9 and in $7 \%$ of patients SOFA score was $>9$. Hyperamylasemia observed in $83.3 \%$ of died and $33.3 \%$ of died patients had increased lipase. There was significant difference between discharged and died patients as regards APACHE II score, SOFA Score, serum amylase and lipase. It could be concluded that SOFA score, APACHEII score, serum amylase and lipase had a role in assessment of severity of acute organophosphorus poisoning but only SOFA score, APACHEII score and serum amylase could be used as predictors of outcome. SOFA score is more useful in predicting mortality, and easier and simpler than the APACHEII and serum amylase. From the previous results, our study recommends that predictors of outcome (APACHE II score, SOFA score and serum amylase) should be assessed routinely and as early as possible to evaluate the severity, improve the course of management and deciding the pathway of care.
\end{abstract}

\begin{tabular}{l|l} 
Keywords & Organophosphate, APACHE II score, SOFA score, ICU
\end{tabular} 


\section{Introduction}

$\mathrm{O}$ rganophosphorus (OP) poisoning is a major medical problem worldwide. The World Health Organization has estimated that more than 300 million case of acute pesticide poisoning occur worldwide each year, and that most of these cases are due to OP intoxication. These OP compounds are likely to have more toxicity in developing countries due to its easy availability and less awareness which results in high morbidity and mortality (Kumar et al., 2010; Kim et al., 2013).

Organophosphorus poisoning remains an important cause of morbidity and mortality, but no definite parameters have been identified as predictors of outcome. Prediction of morbidity at presentation might help in decision making in places of limited resources like rural settings in developing countries (Muley et al., 2014).

Scoring systems have been continuously developed to predict outcome in patients with severe illness, to improve resource allocation and to assist in clinical decision-making particularly for intensive care unit patients. Acute physiology and chronic health evaluation II (APACHE II) system serves as a useful index for evaluating the severity of poisoning due to multiple organ system involvement. Moreover, the Sequential Organ Failure Assessment (SOFA) score has been shown to have a good correlation between predicted and observed patient outcome (Williams and Gannon2009; Mahrous et al., 2011; Kim et al., 2013).

The quest for biomarkers in relation to OP compound poisoning started quite a long time back. OP labeled albumin in plasma, blood $\beta$ glucuronidase and paraxonase status have been suggested by some researchers to be very reliable marker for both diagnosis and prognosis. But all these assays are dependent on specialized laboratories and costly. So cheap and easily measurable biomarkers having prognostic value is the need of the hour (Sen et al., 2014).

OP poisoning is associated with various biochemical abnormalities among which hyperamylasemia is well documented. Serum amylase could be considered as a better predictor of severity followed by lipase (Sumathi et al., 2014).

\section{Aim of the work}

The aim of this work is to evaluate the role of APACHE II score, SOFA score, serum amylase and lipase in assessing severity and outcome of acutely organophosphate poisoned patients presented to the PCC of Ain Shams University Hospitals which may help in improving the course of management and deciding the pathway of care.

\section{Patients and methods}

This is a retrospective and prospective study of 200 acutely intoxicated patients admitted to PCC of Ain Shams University Hospitals (100 patients in the retrospective part and 100 patients in the prospective part of the study). An approval from the ethical committee was taken. In the retrospective part of the study information was collected from the sheets of the patients and an informed written consent has been obtained from each patient or from his/her caregiver for inclusion in the prospective part of the study.

\section{Patient is Selection Criteria:}

The selected patients were of both sexes with acute OP exposure.The diagnosis of OP poisoning was based on the following criteria as guided by Lee, (2001):

- History of exposure to OP compounds.

- Characteristic toxidrome of OP toxicity

- Improvement of Muscarinic symptoms and signs after atropine administration.

- Low serum pseudo-cholinestrase activity.

\section{Exclusion Criteria:}

- Patients with history of severe cardiac, pulmonary, renal impairment or nephritic syndrome.

- Patients with any of the following which reduce pseudocholinestrase activity (Parenchymal liver disease, acute infection, metastatic carcinoma, malnutrition, iron deficiency anemia, dermatomyositis, early pregnancy and Patients taking toxicants (cocaine, carbon disulfide, benzalkonium salts, organic mercury compounds, ciguatoxins, and solanines) or drugs (birth control pills and metoclopramide).

The following data was collected from the sheet of each patient:

1. Sociodemographic data including age and sex of the patients.

2. APACHE II and SOFA scores were calculated to each patient admitted

The APACHE II score was calculated in accordance with the standard methodology, clinical and biological data obtained during the first 24 hours of ICU stay as well as the age and chronic health status of the patients. If a variable was measured more than once during that time, the worse value was used. In APACHE II, there are 12 physiological variables. The effects of age and chronic health status are incorporated directly into the model, weighted according to their relative impact, to give a single score. The APACHE II score ranges from 0 to 71 points (Vincent and Moreno, 2010). The SOFA score was calculated in accordance with the standard methodology, during stay of each patient In SOFA score, six organ systems are weighted to give the final score 
and ranges from 0 to 24(Williams and Gannon, 2009).

3. Biochemical analysis of serum amylase and lipase were estimated.

Serum amylase levels between 0 and $95 \mathrm{u} / \mathrm{l}$ and serum lipase levels between 0 and $60 \mathrm{u} / \mathrm{l}$ (Ahmed et al., 2009). Serum lipase level was measured to exclude acute pancreatitis due to OP poisoning and to know whether increased serum amylase was of pancreatic or salivary origin. Serum $\alpha$-amylase has been measured on admission. Serum $\dot{\alpha}-$ amylase was measured by a kinetic method using Spectrum GALG2-CNP kit. Serum lipase has been measured on admission and was measured by a colorimetric test, kinetic method using Spectrum DGMRE kit.

4. Outcome of the patients:

The patients were classified according to the outcome into discharged and died patients

5. Complications:

All patients were observed during the study to the complications developed during admission in the hospital.

\section{Statistical Analysis}

The obtained results were revised, coded and organized for statistical analysis using SPSS (Statistical Package for Social Science) version 20 software. Mean, standard deviation $( \pm S D)$ was done for numerical data. Frequency and percentage were obtained for non-numerical data. Comparison between outcome groups was tested by using Chisquare test for qualitative data, and by using Independent t-test for quantitative data. Correlation analysis (using Pearson's method) was used to assess the strength of association between two quantitative variables. Linear regression analysis was used to identify significant predictors of outcomes. P-value less than 0.05 was considered statistically significant. Receiver operating characteristic curve (ROC) was used to assess predictors of outcome with its cut off points, sensitivity, specificity, positive Predictive Value and negative Predictive Value. According to Peat and Barton (2005), ROC curve determines sensitivity, specificity, and also can determine the significance of a test in predicting certain disease using the Area under the Curve (AUC) and its significance.

\section{Results}

A retrospective and prospective study was carried out on 200 patients of acute OP poisoning admitted to the Poison Control Center (PCC), Ain Shams University Hospitals. In the current study, the mean age was 23.4 and ranged from 1 month to 63 years. There were $44.5 \%$ of patients in the age group between 18 to $<40$ years and $37 \%$ of patients were in the age group $<18$ years old, $53 \%$ of patients were females and $47 \%$ were males (table, 1). The outcome of the patients as shown in (table, 2) was as the following: 180 patients were discharged representing about (90\%) and 20 patients were died representing about (10\%).

As regard complications developed, table $(3,4)$ showed that $24 \%$ of the patients in the present study developed complications. These complications categorized as $16.5 \%$ of patients developed respiratory failure, $12 \%$ were comatose, and $4 \%$ of patients developed pneumonia. As regard APACHE II score and SOFA score, table $(5, \mathbf{6})$ showed that the mean APACHE II score of patients was 6.37. The APACHE II score ranged between 0 and 38 . There were $76 \%$ of patients had APACHE II score $\leq 9$, while $12.5 \%$ of patients had APACHE II score from 10 to 14, there were $8.5 \%$ of patients had APACHE II score from 15 to 24 and APACHE II score was > 24 in 3\% of patients. The mean SOFA score of patients was 2.34. The SOFA score ranged between 0 and 15. SOFA score in $88.5 \%$ of patients was $\leq 6$, while in $4.5 \%$ of patients SOFA score was from 7 to 9 and in $7 \%$ of patients SOFA score was $>9$.There was significant difference between discharged and died patients as regards APACHE II and SOFA Scores where patients who died had high APACHE II and SOFA Scores than discharged patients. As regard serum amylase and lipase, table (7) showed that there was significant difference between discharged and died patients as regards serum amylase and lipase, where hyperamylasemia observed in $83.3 \%$ of died. $33.3 \%$ of died patients had increased lipase. As shown in table (8) there was significant positive correlation between APACHE II score, SOFA score and serum amylase with the hospital stay duration, total atropine and toxogonin doses received. There was significant positive correlation between lipase and hospital stay duration and total toxogonin dose, but no correlation with total atropine dose. Table (9) showed that significant increase of APACHE II, SOFA scores and also increased level of amylase and lipase in patients who developed complications than those who didn't develop the complications. APACHEII, SOFA scores and serum amylase could be used as predictors of outcome of acute organophosphorus poisoning, while lipase couldn't be used in outcome prediction, table (10). ROC curve analysis to assess the predictor of outcome of OP poisoning (Table 11) showed that the area under the curve for APACHE II score was 0.986, SOFA score was 0.995 and compared to serum amylase was 0.852 Also, it was found that APACHE II score at cut off value > 10 had corresponding sensitivity $100 \%$ and specificity $90.56 \%$, SOFA score at cut off $>5$ had sensitivity $100 \%$ and specificity $90.56 \%$ and serum amylase at cut off $>95$ had sensitivity $83.3 \%$ and specificity $87.5 \%$. The accuracy rate of SOFA score $(99.5 \%)$ was higher than that of APACHE II score (98.6\%) and serum amylase (85.2\%). 
Tale (1): Number and percentage of the studied patients as regard age and sex

\begin{tabular}{|l|c|c|c|}
\hline \multicolumn{2}{|c|}{} & Number & Percentage \% \\
\hline \multirow{3}{*}{ Age in years } & $<18$ & 74 & $37 \%$ \\
\cline { 2 - 4 } & {$[18,40[$} & 89 & $44.5 \%$ \\
\cline { 2 - 4 } & {$[40,60]$} & 33 & $16.5 \%$ \\
\cline { 2 - 4 } & $>60$ & 4 & $2 \%$ \\
\cline { 2 - 4 } & Mean \pm SD & \multicolumn{2}{|c|}{$23.40 \pm 9.97$} \\
\cline { 2 - 4 } & Range & 94 & $47 \%$ \\
\hline \multirow{4}{*}{ Sex } & Male & 106 & $53 \%$ \\
\cline { 2 - 4 } & Female & \multicolumn{2}{|c|}{03} \\
\hline
\end{tabular}

\section{SD: Standard deviation}

Table (2): Number and percentage of the outcome of the studied patients.

\begin{tabular}{|l|c|c|}
\hline Outcome & Frequency & Percentage \\
\hline Discharged & 180 & $90 \%$ \\
\hline Died & 20 & $10 \%$ \\
\hline Total & 200 & $100 \%$ \\
\hline
\end{tabular}

Table (3): Number and percentage of the patients that developed complications during the study.

\begin{tabular}{|l|c|c|}
\hline Complications & N & \% \\
\hline Non complicated & 152 & $76 \%$ \\
\hline Complicated & 48 & $24 \%$ \\
\hline
\end{tabular}

Table (4): Number and percentage of different complications developed during the study.

\begin{tabular}{|l|l|c|}
\hline Type of complication & N & \% \\
\hline Respiratory failure & 33 & $16.5 \%$ \\
\hline Coma & 24 & $12 \%$ \\
\hline Pneumonia & 8 & $4 \%$ \\
\hline Arrhythmias & 5 & $2.5 \%$ \\
\hline Shock & 5 & $2.5 \%$ \\
\hline Intermediate syndrome & 5 & $2.5 \%$ \\
\hline Pancreatitis & 5 & $2.5 \%$ \\
\hline Pulmonary edema & 4 & $2 \%$ \\
\hline Convulsion & 2 & $1 \%$ \\
\hline Relapse & 2 & $1 \%$ \\
\hline Renal failure & 2 & $1 \%$ \\
\hline
\end{tabular}

Table (5): APACHE II and SOFA scores of the studied patient.

\begin{tabular}{|c|c|c|c|}
\hline \multicolumn{2}{|c|}{$($ Total No $=200)$} & Number & Percentage \% \\
\hline \multirow[t]{6}{*}{ APACHE II score } & $\leq 9$ & 152 & $76 \%$ \\
\hline & 10-14 & 25 & $12.5 \%$ \\
\hline & $15-24$ & 17 & $8.5 \%$ \\
\hline & $>24$ & 6 & $3 \%$ \\
\hline & Mean \pm SD & \multicolumn{2}{|c|}{$6.37 \pm 2.26$} \\
\hline & Range & \multicolumn{2}{|c|}{$0-38$} \\
\hline \multirow[t]{5}{*}{ SOFA score } & $\leq 6$ & 177 & $88.5 \%$ \\
\hline & $7-9$ & 9 & $4.5 \%$ \\
\hline & $>9$ & 14 & $7 \%$ \\
\hline & Mean \pm SD & \multicolumn{2}{|c|}{$2.34 \pm 0.36$} \\
\hline & Range & \multicolumn{2}{|c|}{$0-15$} \\
\hline
\end{tabular}


Table (6): Independent t- test statistical analysis of APACHE II and SOFA scores in relation to outcome.

\begin{tabular}{|c|c|c|c|c|c|}
\hline & \multirow{2}{*}{$\begin{array}{c}\text { Total number } \\
=200\end{array}$} & \multirow{2}{*}{$\begin{array}{c}\text { Discharged } \\
\mathrm{N}=180\end{array}$} & \multirow{2}{*}{$\begin{array}{c}\text { Died } \\
N=20\end{array}$} & \multicolumn{2}{|c|}{ Independent t-test } \\
\hline & & & & $\mathbf{t}$ & P-value \\
\hline \multirow[t]{6}{*}{ APACHE II score } & $\leq 9$ & $152(84.5 \%)$ & $0(0 \%)$ & \multirow[t]{6}{*}{-15.452} & \multirow[t]{6}{*}{$<0.001$} \\
\hline & $10-14$ & 22(12.2\%) & $3(15 \%)$ & & \\
\hline & $15-24$ & $6(3.3 \%)$ & $11(55 \%)$ & & \\
\hline & $>24$ & $0(0 \%)$ & $6(30 \%)$ & & \\
\hline & Mean \pm SD & $4.58 \pm 1.52$ & $22.45 \pm 7.61$ & & \\
\hline & Range & $0-24$ & $11-38$ & & \\
\hline \multirow[t]{5}{*}{ SOFA score } & $\leq 6$ & 176(97.8) & $1(5 \%)$ & \multirow[t]{5}{*}{-21.391} & \multirow[t]{5}{*}{$<0.001$} \\
\hline & $7-9$ & $3(1.6 \%)$ & $6(30 \%)$ & & \\
\hline & $>9$ & $1(0.6 \%)$ & $13(65 \%)$ & & \\
\hline & Mean \pm SD & $1.41 \pm 0.57$ & $10.75 \pm 2.46$ & & \\
\hline & Range & $0-10$ & $6-15$ & & \\
\hline
\end{tabular}

Table (7): Independent t- test statistical analysis of serum amylase and lipase in relation to outcome.

\begin{tabular}{|c|c|c|c|c|c|}
\hline \multicolumn{2}{|c|}{ Laboratory parameters } & \multirow{2}{*}{$\begin{array}{c}\begin{array}{c}\text { Discharged } \\
\text { N=88 }\end{array} \\
74(84.1 \%)\end{array}$} & \multirow{2}{*}{$\begin{array}{c}\begin{array}{c}\text { Died } \\
\mathbf{N}=12\end{array} \\
2(16.7 \%)\end{array}$} & \multicolumn{2}{|c|}{ Independent t-test } \\
\hline \multirow{4}{*}{$\begin{array}{l}\text { Amylase } \\
(0-95 \text { u/l) }\end{array}$} & $\leq 95 \mathrm{u} / \mathbf{l}$ & & & \multirow[t]{4}{*}{-6.252} & \multirow[t]{4}{*}{$<0.001$} \\
\hline & $>95 u / \mathbf{l}$ & $14(15.9 \%)$ & $10(83.3 \%)$ & & \\
\hline & Mean \pm SD & $78.02 \pm 26.39$ & $440.66 \pm 193.03$ & & \\
\hline & Range & $3-617$ & $40-1357$ & & \\
\hline \multirow[t]{4}{*}{ Lipase (0- 60 u/l) } & $\leq 60 \mathrm{u} / \mathrm{l}$ & $87(98.9 \%)$ & $8(66.7 \%)$ & \multirow[t]{4}{*}{-5.281} & \multirow[t]{4}{*}{$<0.001$} \\
\hline & $>60 u / 1$ & $1(1.1 \%)$ & $4(33.3 \%)$ & & \\
\hline & Mean \pm SD & $29.92 \pm 12.006$ & $69.66 \pm 27.47$ & & \\
\hline & Range & $0-93$ & $21-185$ & & \\
\hline
\end{tabular}

Table (8): Pearson correlation among hospital admission duration, total atropine dose and total toxogonin dose in relation to APACHE II score, SOFA score, serum amylase and lipase in the present study.

\begin{tabular}{|c|c|c|c|c|c|c|}
\hline \multirow{2}{*}{ Variable } & \multicolumn{2}{|c|}{ H.A duration } & \multicolumn{2}{c|}{ Total atropine dose (mg) } & \multicolumn{2}{c|}{ Total toxogonin dose (gm) } \\
\cline { 2 - 7 } & $\mathbf{r}$ & $\mathbf{p}$-value & $\mathbf{r}$ & $\mathbf{p}$-value & $\mathbf{r}$ & $\mathbf{p}$-value \\
\hline APACHE II & 0.566 & $<\mathbf{0 . 0 0 1}$ & 0.443 & $<\mathbf{0 . 0 0 1}$ & 0.467 & $<\mathbf{0 . 0 0 1}$ \\
\hline SOFA & 0.702 & $<\mathbf{0 . 0 0 1}$ & 0.452 & $<\mathbf{0 . 0 0 1}$ & 0.454 & $<\mathbf{0 . 0 0 1}$ \\
\hline Amylase & 0.238 & $\mathbf{0 . 0 1 7}$ & 0.472 & $<\mathbf{0 . 0 0 1}$ & 0.276 & $\mathbf{0 . 0 4 7}$ \\
\hline Lipase & 0.332 & $\mathbf{0 . 0 0 1}$ & 0.094 & $\mathbf{0 . 3 5 5}$ & 0.441 & $\mathbf{0 . 0 0 1}$ \\
\hline
\end{tabular}

r: correlation coefficient $\quad$ H.A duration: Hospital admission duration

Table (9): Independent t-test statistical analysis of APACHE II score, SOFA score, serum amylase and lipase among complicated and non complicated patients in the present study.

\begin{tabular}{|c|c|c|c|c|c|}
\hline \multicolumn{2}{|c|}{ Variable } & \multirow{3}{*}{$\begin{array}{c}\text { Non complicated } \\
\mathbf{N}=\mathbf{1 5 2} \\
3.349 \pm 1.284 \\
\end{array}$} & \multirow{3}{*}{$\begin{array}{c}\text { Complicated } \\
\mathbf{N}=\mathbf{4 8} \\
15.938 \pm 5.122 \\
\end{array}$} & \multicolumn{2}{|c|}{ Independent t-test } \\
\hline & & & & $\mathbf{t}$ & p-value \\
\hline APACHE II & Mean \pm SD & & & -15.558 & $<0.001$ \\
\hline SOFA & Mean \pm SD & $0.961 \pm 0.184$ & $6.729 \pm 2.186$ & -15.237 & $<0.001$ \\
\hline Amylase & Mean \pm SD & $57.903 \pm 22.704$ & $285.179 \pm 120.197$ & -5.162 & $<0.001$ \\
\hline Lipase & Mean士 SD & $27.264 \pm 12.768$ & $53.786 \pm 21.114$ & -4.768 & $<0.001$ \\
\hline
\end{tabular}

$t=$ independent $t$ test,$S D$ : standard deviation 
Table (10): Linear regression analysis of APACHEII score, SOFA score, serum amylase and lipase to detect predictors of outcome.

\begin{tabular}{|c|c|c|c|c|c|}
\hline \multirow{2}{*}{ Model } & \multicolumn{2}{|c|}{$\begin{array}{c}\text { Unstandardized } \\
\text { Coefficients }\end{array}$} & $\begin{array}{c}\text { Standardized } \\
\text { Coefficients }\end{array}$ & \multirow{2}{*}{ T } & \multirow{2}{*}{ P- value } \\
\cline { 2 - 4 } & $\mathbf{B}$ & Std. Error & Beta & & \\
\hline APACHE II & -0.019 & 0.004 & -0.461 & -4.448 & $<\mathbf{0 . 0 0 1}$ \\
\hline SOFA & 0.101 & 0.007 & 1.192 & 13.829 & $<\mathbf{0 . 0 0 1}$ \\
\hline Amylase & 0.000 & 0.000 & 0.175 & 3.344 & $\mathbf{0 . 0 0 1}$ \\
\hline Lipase & 0.001 & 0.001 & 0.072 & 1.518 & $\mathbf{0 . 1 3 2}$ \\
\hline
\end{tabular}

$P$ is considered statistically significant if $\leq 0.05$.

Table (11): Sensitivity, specificity and accuracy rate of predictors of outcome in the current study.

\begin{tabular}{|c|c|c|c|c|c|c|c|}
\hline Variable & Cut off point & AUC & Sensitivity (\%) & Specificity (\%) & PPV (\%) & NPV (\%) & Accuracy rate \\
\hline APACHE II score & $>10$ & 0.986 & 100 & 90.56 & 54.1 & 100 & $\mathbf{9 8 . 6 \%}$ \\
\hline SOFA score & $>5$ & 0.995 & 100 & 90.56 & 71.4 & 100 & $\mathbf{9 9 . 5 \%}$ \\
\hline Amylase & $>95$ & 0.852 & 83.33 & 87.50 & 47.6 & 97.5 & $\mathbf{8 5 . 2 \%}$ \\
\hline
\end{tabular}

AUC: Area under Curve (Receiver Operating Curve), PPV: Positive Predictive Value, NPV: Negative Predictive Value

\section{Discussion}

Organophosphates are one of the most common causes of poisoning, especially in developing countries, with high morbidity and mortality. This study aimed at to evaluate the role of APACHE II score, SOFA score, serum amylase and lipase in assessing the severity and outcome of acute organophosphorus poisoning presented to the PCC of Ain Shams University Hospitals which may help in improving the course of management and deciding the pathway of care. In this study 180 patients (90\%) improved and were discharged and 20 patients (10\%) died during treatment in the PCC. This was in agreement with results reported by Bilal et al. (2014) where the recovery in their results was observed in $90 \%$ of cases and death was observed in $10 \%$ cases. This ratio was close to this obtained by Godhwani et al. (2004) where it was $12 \%$. Yamashita et al. (1997) reported a higher rate of 25\%, while Dharmani and Jaga, (2005) reported fatality in hospital-based surveys of OP poisoning as high as $46 \%$.

In the present study the mean age for the patients was 23.4 years and most of patients were belonging to teenager and middle age group (18 40 years) represent $44.5 \%$ of the patients in the study. This finding was in accordance with Ahmed et al. (2014) and Banday et al. (2015) in which the incidence was highest in patients aged less than 40 years. There were only $2 \%$ of all patients included in the study above age of 60 years and this was in agreement with Chintale et al. (2016). This could be explained by the vulnerability to various emotional conflicts that can happen during this phase (teenager and middle age groups) of life in which the people are most ambitious and productive (Banday et al., 2015).

In the present study females were affected more than males. $53 \%$ of patients were females and 47\% were males with a female to male ratio 1.1: 1 . This was in agreement with Chaturvedi et al. (2014) and Gündüz et al. (2015) study in which also females were affected more than males. Banerjee et al. (2012) postulated in their study that male to female ratio was $1: 1.38$. On contrary to many other studies males were more affected than females (Muley et al., 2014; Sumathi et al., 2014; Ghaniger et al., 2016).Causes of female predominance in the current study may be attributed to emotional liability of female to life stress and strains in our society than male also due to easy availability of OP compounds in the home as a household product (Z'gambo et al., 2016).

In the current study $24 \%$ of patients developed complications. The most frequent type of complication was respiratory failure in 16.5\% followed by coma in $12 \%$. Bilal et al. (2014) agreed with these results, Also Chintale et al. (2016) reported that respiratory failure was the most common complication.

In the current study the mean APACHE II score of the studied patients was 6.37, APACHE II score in discharged, died, noncomplicated and complicated patients was $4.58 \pm 1.52$, $22.45 \pm 7.61$, $3.35 \pm 1.28$ and $15.94 \pm 5.12$ respectively 
$(\mathrm{P}<0.001)$. The mean SOFA score of the studied patients was 2.34, SOFA score in discharged, died, noncomplicated and complicated patients was $1.41 \pm 0.57, \quad 10.75 \pm 2.46, \quad 0.961 \pm 0.18$ and 6.729 \pm 2.19 respectively $(\mathrm{P}<0.001)$. There was statistically significant association between high APACHEII score and high SOFA score and severity of OP poisoning. This was in agreement with Singh et al. (2011) and Kim et al. (2013) studies in which APACHE II score and SOFA score were high in nonsurvivors than survivors.Also, Jabalameli et al. (2006) reported that APACHE II Score was highest in died patients and correlated with OP poisoning complications. These results also go with those of Kang et al. (2009) who reported that The APACHE II score was high in patients who died from acute organophosphate poisoning and those who had complications especially respiratory failure .Also, this was similar to results of Vosylius et al. (2005) who reported that the non-survivors had higher SOFA score than the survivors and the emergence of more severe organ dysfunction was strongly associated with mortality Sam et al. (2009) said that APACHE II score is a simplified physiological score assessing the severity of OP poisoning.

In the current study seum amylase in discharged, died, noncomplicated and complicated patients was $78.02 \pm 26.39,440.66 \pm 193.03,57.9 \pm$ 22.7 and $285.18 \pm 120.2$ respectively $(\mathrm{P}<0.001)$. Lipase in discharged, died, noncomplicated and complicated patients was $29.92 \pm 12.0$, $69.66 \pm 27.47, \quad 27.26 \pm 12.77$ and $53.79 \pm 21.11$ respectively $(\mathrm{P}<0.001)$. OP poisoning is associated with many biochemical abnormalities. Among which hyperamylasemia often noted in cases of OP poisoning, may be due to the fact that acute pancreatitis is caused by excessive cholinergic stimulation of pancreas by OP compounds (Sumathi et al., 2014).Hyperamylasemia was reported in this study more in died and complicated than discharged and noncomplicated patients. Thus this increase in serum amylase level was coinciding with severity, the same result was reported by Alawadi (2000). These results go with Sumathi et al. (2014) who reported significant association with severity of OP poisoning with respect to amylase and lipase.Serum amylase and lipase can be used as a marker for recognition of severity in op poisoning (Adhil and Sudharsan, 2015). Serum amylase levels may be considered as a marker of Organophosphorous intoxication, since it enables the early recognition of severity and to identify those at risk of developing the complications of Organophosphorous poisoning (Salame and Wani, 2017). Among one hundred patients in the present study, hyperamylasemia was found in twenty four patients (24\%) while hyperlipasemia was seen in 5 patients (5\%). This was in agreement with Chaturvedi et al. (2014) where hyperamylasemia was more frequently seen in organophosphate poisoning. Sahin et al. (2002) concluded that acute pancreatitis was not a rare complication of organophosphorus poisoning. Acute pancreatitis is frequent in $\mathrm{OP}$ poisoning and increased serum amylase is less specific and sensitive. Hence, serum lipase measurement may be useful in patients with increased amylase levels for early diagnosis of pancreatitis (Lee et al., 1998; Sumathi et al., 2014). As patients with hyperamylasemia had normal serum lipase, thus hyperamylasemia was contributed to be of salivary origin and not of pancreatic origin, this finding agreed with (Clark, 2002).A previous report by Lee et al. (1998) explained that hyperamylesemia in OP poisoned patients may be due to excessive muscarinic stimulation, severe acidosis, or shock with subsequent hypersecretion of salivary glands.

In the current study there was positive correlation between APACHEII score, SOFA score, serum amylase and duration of hospital admission, total dose of atropine and toxogonin needed. While there was positive correlation between lipase and hospital stay duration and total toxogonin dose received by the patients, but no correlation with total atropine dose. This was in agreement with Coskan et al. (2015), Hiremath et al. (2016) and Dong et al. (2017) where it was observed that patients with high APACHEII score and SOFA score needed longer duration of hospital stay and higher atropine and pralidoxime doses. Also, Salame and Wani, (2017) reported that increased serum amylase in severe cases needed high doses of antidotes. Sumathi et al. (2014) found that seum lipase didn't show significant correlation with plasma cholinesterase.

By using linear regression analysis with the indices studied in the current work showed that APACHEII score, SOFA score and amylase were highly significantly increased with death hence could be used as predictors of outcome. While lipase couldn't be used as outcome predictor. This was similar to results of Kim et al. (2013), Sam et al. (2009) and Sumathi et al. (2014). SOFA score is significantly associated with mortality and has strong discriminative power for predicting mortality (Kim et al., 2013). Sam et al. (2009) said that APACHE II score is a simplified physiological score predicting and assessing the severity and mortality of OP poisoning and Kang et al. (2009) found that APACHE II score was significant predictor of mortality. Serum amylase could be considered as a better predictor of severity and outcome in acute OP poisoning (Sumathi et al., 2014) In contrast, Adhil and Sudharsan, (2015) reported that lipase can be used as a marker for 
recognition and predicting outcome in OP poisoning.

In the current study, ROC curve analysis to assess the predictor of outcome of OP poisoning showed that the area under the curve for APACHE II score was 0.986, SOFA score was 0.995 and compared to serum amylase was 0.852 Also, it was found that APACHE II score at cut off value $>10$ had corresponding sensitivity $100 \%$ and specificity $90.56 \%$, SOFA score at cut off $>5$ had sensitivity $100 \%$ and specificity $90.56 \%$ and serum amylase at cut off $>95$ had sensitivity $83.3 \%$ and specificity $87.5 \%$. Also, in this study the accuracy rate of SOFA score (99.5\%) was higher than that of APACHE II score (98.6\%) and serum amylase (85.2\%).These results go with those of Sumathi et al. (2014) where the area under the curve for SOFA score was 0.896 and for APACHE II score was 0.716 , The accuracy rate of SOFA score $83.2 \%$ was higher than that of APACHE II score $67.9 \%$. Kim et al. (2013) showed that serum amylase was 0.714 . And the accuracy rate of serum amylase was $71.4 \%$.

SOFA score had the highest accuracy and predictive ability followed by APACHE II score while serum amylase was the least one. This was in agreement with Baradari et al. (2016) and Shabir and Maqbool, (2017) "SOFA score is able to predict outcome significantly". Kim et al. (2013) concluded that SOFA score is more useful in predicting mortality, and easier and simpler than APACHE II score.

\section{Conclusion}

SOFA score, APACHEII score, serum amylase and lipase had a role in assessment of severity of acute organophosphorus poisoning but only SOFA score, APACHEII score and serum amylase could be used as predictors of outcome. SOFA score is more useful in predicting mortality, and easier and simpler than the APACHEII and serum amylase.

Such objective information is routinely collected in the emergency department and can help emergency physicians to quickly detect the severity of OP poisoned patients and predict the poor outcomes of those who need intensive care admission.

\section{Acknowledgment}

The authors thank the Directors, the medical and nursing staff of the Poison Control Centre, Ain Shams University hospital for their help and support.

\section{References}

Adhil S and Sudharsan S (2015): Estimation of serum amylase and lipase levels in correlation with clinical outcome of OP poisoning. Int. J. Modn. Res. 3(10): 849-851.

Ahmed A, Begum I, Aquil N et al., (2009): Hyperamylasemia and acute pancreatitis following organophosphate poisoning. Pak J Med Sci. 25(6):957-961.

Ahmed K, Sainath C and Ahmed P (2014): A cross sectional study of estimation of plasma pseudo cholinesterase and its correlation to mortality among organophosphorous poisoning patients, Indian Journal of Basic and Applied Medical Research. 3(3): 285-291.

Alawadi H (2000): Results. A prospective study of the toxic effects in patients with OPs insecticide posining.M.Sc thesis at faculty of Medicine Ain Shams University.

Banday T, Tathineni B, Desai $\mathrm{M}$ et al., (2015): Predictors of morbidity and mortality in organophosphorus poisoning: A case study in rural hospital in Karnataka, India, N Am J med sci.7(6): 259-265, doi: 10.4103/19472714.159331

Banerjee I, Tripathi S and Roy A (2012): Clinicoepidemiological characteristics of patients presenting with organophosphorus poisoning, North American Journal of Medical Sciences. 4 (3): 147-150, doi: 10.4103/1947-2714.93884

Baradari A, Firouzian A, Davanlou A et al., (2016): Comparsion of patients' admission, mean and highest SOFA scores in prediction of ICU mortality. 28:343-347.

Bilal M, Khan Y, Ali S and Naeem A (2014): the pattern of organophosphorus poisoning and its short term outcomes in various socioeconomic groups. KJMS. 7(1), P: 11-16.

Chaturvedi A, Dutta S, Sarkar S et al., (2014): Prevalence of hyperamylasemia and acute pancreatitis in organophosphate poisonings. Journal of dental and medical sciences. 13(1):59-62.

Chintale K, Patne S and Chavan S (2016): Clinical profile of organophosphorus poisoning patients at rural tertiary health care centre, International Journal of Advances in Medicine. 3(2):268-274, doi: 10.18203/2349-3933.ijam20161074

Clark R (2002): Pesticides. Insecticides: Organic Phosphorous Compounds and Carbamates. In: Goldfrank's Toxicologic Emergencies, 7th edition, Appleton ang Lange, Stanford, pp: 1346-60.

Coskun R, Gundogan K, Sezgin G et al., (2015): A retrospective review of intensive care management of organophosphate insecticide poisoning: Single center experience, Nigerian Journal of Clinical Practice. 18(5): 644-650, doi: 10.4103/1119-3077.158962

Dharmani C and Jaga K (2005): Epidemiology of acute organophosphate poisoning in hospital emergency room patients. Rev Environ Health. 20(3): 215-247.

Dong H, Weng Y, Liu J et al., (2017): Clinical emergency treatment of 68 critical patients with sever organophosphorus poisoning and 
prognosis analysis after rescue. 96(25):723, doi:10.1097/MD.0000000000007237.

Ghaniger M, Hemamalini G and Sanjana K (2016): Prevalence of acute pancreatitis in organophosphate poisoning in correlation with elevated serum amylase and lipase level in a tertiary care hospital. Sch.J.App.Med.Sci. 4(3):963-965.

Godhwani S, Godhwani S and Tulsiani K (2004): Management of organic insecticide poisining in intensive care unit (I.C.U).Indian J. Anaesth. 48(4): 295-393.

Gündüz E, Dursun R, Icer M et al., (2015): Factors affecting mortality in patients with organophosphate poisoning. Journal of Pakistan Medical Association .65(9): 967-972.

Hiremath P, Rangappa P, Jacob I et al., (2016): Pseudocholinesterase as a predictor of mortality and morbidty in organophosphorus poisoning. Indian J Crit Care Med. 20(10):601-604.

Jabalameli M, Eizadi N and Saghaie M (2006): Predictive outcome of toxicity with organophosphate based on APACHE II scoring system in intensive care unit. European journal of anaesthesiology. 23:206.

Kang E, Seok S, Lee K et al., (2009): Factors for determining survival in acute organophosphate poisoning, Korean J Intern Med. 24, P: 362-367, doi: 10.3904/kjim.2009.24.4.362

Kim Y, Yeo J, Kang M et al., (2013): performance assessment of the SOFA, APACHE II scoring system, and SAPS II in Intensive Care Unit Organophosphate poisoned patients. J Korean Med Sci. 28:1822-1826.

Kumar S, Fareedullah M, Sudhakar Y et al., (2010): Current review on organophosphorus poisoning. Arch Appl Sci Res. 2:199-215.

Lee P (2001): Clinical features of patients with acute organophosphate poisoning requiring intensive care. ICU Med; 27:694-699.

Lee W, Yang C and Deng J (1998): The clinical significance of hyperamylesemia in organophosphate poisoning. J Toxicol Clin Toxicol. 36(7): 673-81.

Mahrous A, Mohy K, Amany A et al., (2011): Comparison of the accuracy of two scoring systems in predicting the outcome of organophosphate intoxicated patients admitted to intensive care unit (ICU). Egyptian Journal of Forensic Sciences. 1: 41-47

Muley A, Shah C, Lakhani J et al., (2014): To identify morbidity and mortality predictors in acute organophosphate poisoning. Indian J Crit Care Med. 18:297-300.
Peat J and Barton B (2005): Medical Statistics: A Guide to Data Analysis and Critical Appraisal (1st ed.). Copyright (C) 2005 by Blackwell Publishing Ltd, Chapter 10.

Sahin I, Onbasi K, and Sahin H (2002): The prevalence of pancreatitis in organophosphate poisonings. Hum Exp Toxicol. 21: pp 175-77.

Salame R and Wani A (2017): Study of serum amylase levels in organophosphate poisoning. International Journal of Biomedical and Advance Research . 8(12): 450-454.

Sam K, Kondabolu K, Pati D et al., (2009): Poisoning severity score, APACHE II and GCS: Effective clinical indices for estimating severity and predicting outcome of acute organophosphorus and carbamate poisoning. J Forensic Leg Med. 16:239-286.

Sen R, Nayak J and Khadanga S (2014): Study of serum cholinesterase, CPK and LDH as prognostic biomarkers in Organophosphorus Poisoning. Int J Med Res Rev. 2(3):185-189

Shabir A and Maqbool M (2017): Accuracy of SOFAscore in predicting outcome in medical patients with various diagnosis in intensive care unit.International Journal of Contemporary Medical Research. 4(1):77-83.

Singh O, Javari Y, Juneja D et al (2011): Profile and outcome of patients with acute toxicity admitted in intensive care unit: Experiences from a major corporate hospital in urban India. Indian $\mathrm{J}$ Anaesth. 55:370-4.

Sumathi M, Kumar S, Shashidhar K et al., (2014): Prognostic Significance of Various Biochemical Parameters in Acute Organophosphorus Poisoning. Toxicol Int. 21(2): 167-171.

Vincent J and Moreno R (2010): Clinical review: Scoring systems in the critically ill. Critical Care. 14:207.

Vosylius S, Sipylaite J and Ivaskevicius J (2005): Sequential Organ Failure Assessment Score as the Determinant of Outcome for Patients with Severe Sepsis. Croat Med J. 45:715-720.

Williams L and Gannon J (2009): Use of the SOFA score in pandemic influenza - a prospective study. JICS.10:179-182.

Yamashita M, Tanaka J and Ando Y (1997): Human mortality in organophosphate poisonings. Vet Hum Toxicol. 39(2):84-85.

Z'gambo J, Siulapwa Y and Michelo C (2016): Pattern of acute poisoning at two urban referral hospitals in Lusaka, Zambia, BMC Emergency Medicine. 16(2): 2-8, doi: 10.1186/s12873-016-0068-3 


\section{الملخص العربي}

\section{دور اباتش الثانف وسوفا و الاميليز المصلى والليباز في تقييم شدة ونتائج التسمم الحاد بالمركبات الفسفورية العضوية}

منى القطب موسى ا و سهير على محمدو مها عبدالحميد هلال و مروه أحمد حسب النبى و نايل عبدالحميد زكىץ

يعتبر التنمم بالمركبات الفوسفورية العضوية هو المسؤول عن نسبه كبيرة من حالات المر اضة و الوفيات فى جميع انحاء العالم وخاصة

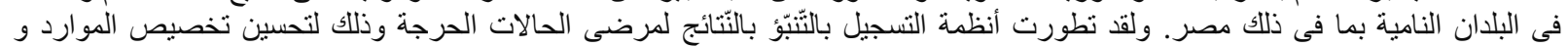

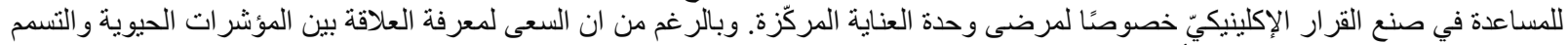

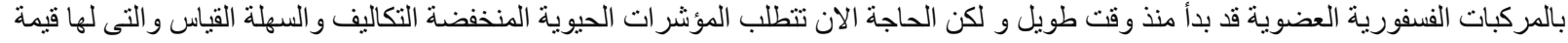

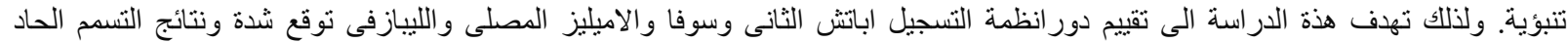

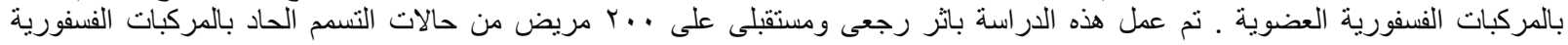

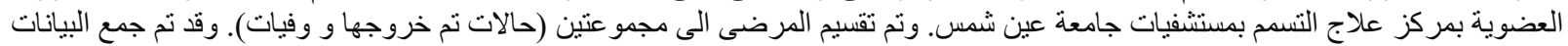

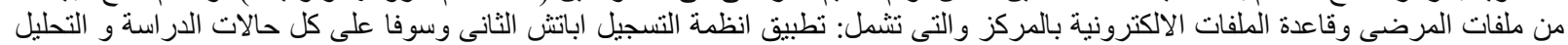

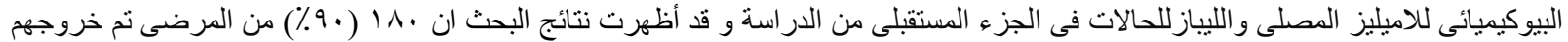

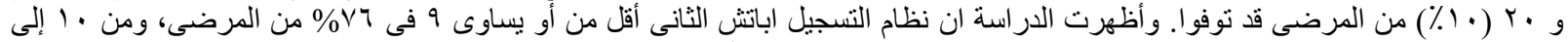

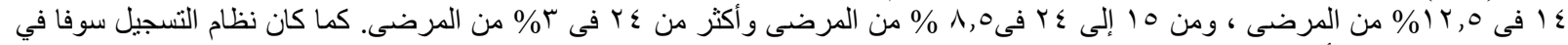

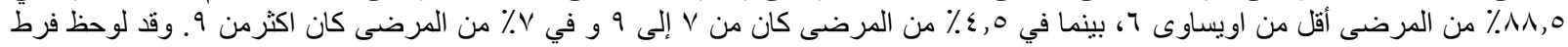

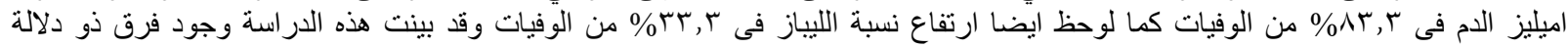

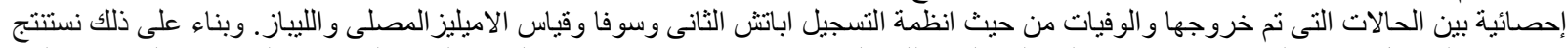

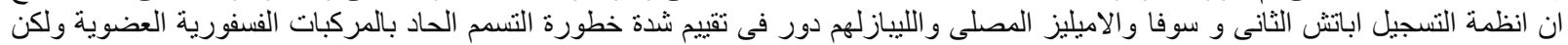

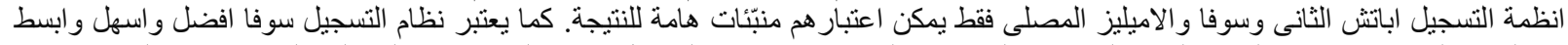

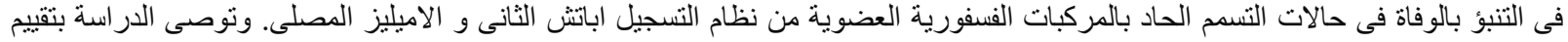

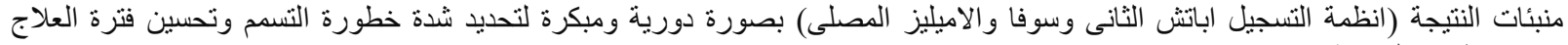
وتقرير طريق الرعاية.

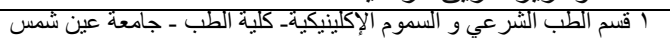

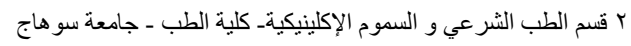

